\title{
In Vitro Studies of Antifungal Activity of Colloidal Silver against Important Plants Pathogens
}

\author{
Oana VENAT ${ }^{1,3}$, Beatrice IACOMI ${ }^{2}$, Adrian G. PETICILA ${ }^{1 *}$ \\ ${ }^{1}$ University of Agronomic Sciences and Veterinary Medicine, Faculty of Horticulture, 59 Marasti Blvd., District I, \\ 011464 Bucharest, Romania; oana.venat@gmail.com; apeticila@gmail.com (*correspondingauthor) \\ ${ }^{2}$ University of Agronomic Sciences and Veterinary Medicine, Faculty of Agriculture, \\ 59 Marasti Blvd., District 1, 011464 Bucharest,Romania; b.iacomi@yahoo.fr \\ ${ }^{3}$ University of Agronomic Sciences and Veterinary Medicine, Research Centre for Studies of Food and Agricultural Products Quality, \\ 59 Marasti Blvd., District 1, 011464 Bucharest, Romania
}

\begin{abstract}
Colloids and especially silver are increasingly used in a variety of worldwide applications because of their potential antimicrobial activity and their plasmotic and conductivity properties. This research reports the fungitoxic properties of colloidal silver on mycelial growth of important plant pathogens: Alternaria brassicicola, Botrytis cinerea, Aspergillus flavus, Aspergillus niger, Fusarium culmorum, Fusarium oxysporum, Penicillium digitatum and Sclerotinia sclerotiorum. Although variable responses towards each compound were observed within the species the results revealed a clear reaction to limiting mycelium growth relative to various concentration of Colloidal silver (CS). Results were expressed as effective concentrations which inhibit mycelial growth by $50 \%$ and $90 \%$ respectively (EC50 and EC90). Efficiency of colloidal silver on mycelial growth inhibition of different isolates based on EC50 have the following values: $3.69 \mathrm{ppm}$ for Alternaria brassicicola, $7.32 \mathrm{ppm}$ for Botrytis cinerea, $18.21 \mathrm{ppm}$ for Aspergillusflavus, $10.43 \mathrm{ppm}$ for Aspergillus niger, $11.99 \mathrm{ppm}$ for Fusarium culmorum, 12.27 ppm for Fusarium oxysporum, $10.82 \mathrm{ppm}$ for Penicillium digitatum and $6.34 \mathrm{ppm}$ for Sclerotinia. According to the obtained results the antifungal activity of colloidal silver particles as biocide has potential for using it as a non-aggressive treatment in horticulture and sustainable horticulture.
\end{abstract}

Keywords: antifungal activity; colloidal silver; plant pathogens

Abbreviations: Craft Colloidal Silver - CCS; CS - colloidal silver; EC50 - effective concentration which inhibits mycelial growth by $50 \%$; EC 90 - effective concentration which inhibits mycelial growth by $90 \%$; Medicer Colloidal Silver - MCS

\section{Introduction}

The presence of silver in community health life dates back to the eighteenth century when silver nitrate $\left(\mathrm{AgNO}_{3}\right)$ was used to treat ulcerations (Klasen, 2000). One hundred years later, the antimicrobial features of silver ions are officially acknowledged by FDA's decision to accept using silver colloids in the management of burns (1920) (Moore and Payne 2004). Nowadays, there are clinical trials covering the colloidal silver's biocidal action although standards on application procedures are scarce and the use of silver colloids as natural biocidal product in plant cropping is a brand-new orientation in the field of integrated crop (Aktar et al., 2009). Silver nanoparticles come second in the international line of international research in agriculture after emulsions/lipids and polymers (Gogos et al., 2012).
Attempts are made in the field of integrated disease and pest management to replace pesticides with natural biocides that harm pest, restrict diseases and lead to the preservation of useful fauna and flora. The research studies conducted so far follow the line outlined by the concern for the use of natural biocides to preserve biodiversity and mitigate the impact of fungicide resistance some pathogens are increasingly demonstrating (Frac Code List, 2018; IacomiVasilescu et al., 2004).

In vitro studies on pathogens and on the antibacterial and antifungal activity of silver colloids are few despite their undeniable growth-inhibiting action and are generally placed in the field of nanotechnologies. Silver nanoparticles turned out to be efficient in inhibiting the mycelial growth (more than 90\%) of Sclerotium cepivorum which is responsible for the white rot of onion, at a concentration of 7 ppm (Jung et al., 2010). 
534

The effect of silver nanoparticles treatments on seed borne fungi of cucumber was tested (Ziedan and Moataza, 2016). It was noticed that mycelial growth of Alternaria alternata and Fusarium oxysporum in the presence of silver nanoparticles was fully inhibited at concentration levels of $10 \mathrm{ppm}$ and $15 \mathrm{ppm}$ respectively. The same study reveals that pre-emerging treatments based on nano-silver solutions fully annihilated Aspergillus flavus, Fusarium oxysporum and Tricoderma spp. off the cucumber seeds.

The in vitro mycelial growth of Corynespora cassicola, Cylindrocarpon destructans and Alternaria solani, as well as of Fusarium graminearum, was also inhibited from a concentration of $50 \mathrm{ppm}$ (Kim et al., 2012) and $20 \mathrm{ppm}$ (Soltanloo et al., 2010) respectively.

Matters related to plasmatic changes driven by silver ion absorption, inhibition or non-inhibition of evolving processes, as well as the remanence in the fruit for feed species are yet to be studied.

Under the said circumstances, the study aimed at highlighting the biological action of colloidal silver in inhibiting certain plant pathogens, being as far as we know amongst the first studies of this kind to have ever been conducted in Romania.

\section{Materials and Methods}

Research studies were conducted in the Phytopathology Laboratory, Plant Science Department, Faculty of Agriculture, University of Agronomic Sciences and Veterinary Medicine Bucharest.

\section{Biological material}

Fungal isolates and growth conditions

The fungi used in this study are listed in Table 1 . All the strains were purified by monospore isolation and maintained on malt agar medium (malt extract 20 g, agar 20 $\mathrm{g}$ in $1 \mathrm{~L}$ distilled water) at $4^{\circ} \mathrm{C}$. Fresh subcultures were made by transferring hyphal plugs to potato dextrose agar (PDA) medium to obtain inocula for sensitivity tests. Six Romanian fungal isolates were obtained from commercial radish seed lots (Aspergillus flavus - Af, Aspergillus niger - An 1 ), vegetables (Botrytis cinerea - Bcl from tomatoes fruits, Sclerotinia sclerotiorum- Ss1 and Fusarium oxysporum - F1 from cucumbers fruits) and lemons (Penicillium digitatum Pd) and identified using standard criteria, based on colony/conidiophores and conidia morphology. Two from our eight tested isolates, Alternaria brassicicola - Abra 43 and Fusarium culmorum - F065 were provided by Université d'Angers, France (IRHS Fungisem).

\section{Antimicrobials}

The tested compounds were Medicer colloidal silver (MCS) - as water with colloidal silver, as food supplement on market, the manufacturer's listed ingredients being CS $20 \mathrm{mg}, 20 \mathrm{ppm}$ concentration in 11 water, $100 \%$ reverseosmosis pure water and Craft Colloidal Silver (CCS), product which was obtained using a device bought from the US based on 999 fineness silver bars, demineralized and deionized water, maximum concentration of $20 \mathrm{ppm} \mathrm{l}^{-1}$.

\section{Assay on mycelium}

Agar disks ( $8 \mathrm{~mm}$ in diameter) were cut from the margin of a 7-day-old colony growing on PDA and were transferred to PDA medium supplemented with the CS at final concentrations $3.75,7.5$ and $15 \mathrm{ppm}$. Three replicates were used per treatment. For each active ingredient and concentration, inhibition of radial growth (product efficacy) compared with the untreated control was calculated after 7 days of incubation at $24^{\circ} \mathrm{C}$, in the dark. Results were expressed as effective inhibitory concentration EC50 and EC90 (the concentration which reduced mycelial growth by $50 \%$ and $90 \%$ respectively) determined by regressing the inhibition of radial growth values (\% control) against the values of the tested product concentrations.

\section{Results}

In vitro effects of colloidal silver on mycelial growth

Craft colloidal silver (CCS) fully inhibited (100\%) the mycelial growth of Sclerotinia sclerotiorum at a concentration level of $7.5 \mathrm{ppm}$. As for the isolates of Alternaria brassicicola, Botrytis cinerea, full inhibition of mycelial growth was only witnesses at $15 \mathrm{ppm}$ concentrations. It is worth noticing that Alternaria brassicicola (Abra 43) colonies demonstrated distinctive lysis signs, concentric ring growth and colour variations against the control sample in the presence of colloidal silver (Fig. 1). The conidia examined under the microscope in the presence of $15 \mathrm{ppm}$ CCS revealed visible changes in the spore cellular membrane and impact on their melanisation (Fig. 2).

A $76.19 \%$ inhibition of the mycelial growth on the Penicillium digitatum was noticed at $16 \mathrm{ppm}$. The two Fusarium isolates studied demonstrated a similar behaviour in the presence of CCS as the mycelial growth was inhibited by $72.22 \%$ at $15 \mathrm{ppm}$. The Aspergillus flavus and Aspergillus niger isolates were less sensitive in the presence of CCS, with a normal growth of colonies at 3.75 and $7.5 \mathrm{ppm}$ concentration levels. The mycelial groth inhibition was exclusively noticed at $15 \mathrm{ppm}$ (40.48\% for Aspergillus flavus and $57.14 \%$ for Aspergillus niger).

Medicer Colloidal Silver (MCS) fully inhibited (100\%) the mycelial growth of Sclerotinia sclerotiorum isolate at a concentration level of $15 \mathrm{ppm}$. Its efficacy reached $57.14 \%$ with the concentration going down to $7.5 \mathrm{ppm}$ (Table 2). It will be noted that this pathogen was sensitive towards both colloidal products tested, efficacy going up to $100 \%$ at concentrations of $15 \mathrm{ppm}$. Nevertheless, CCS fully inhibited the mycelial growth of Sclerotinia sclerotiorum and also reached $100 \%$ efficacy at $7.5 \mathrm{ppm}$ (Fig. 3).

MCS also proved its efficacy in inhibiting the mycelial growth of Botrytis cinerea with values reaching $75.73 \%$ and $94.17 \%$ at concentration levels of 7.5 and $15 \mathrm{ppm}$ respectively. Lower efficacy was demonstrated on other test isolates (between $31.31 \%$ and $36.36 \%$ ), even at a maximum concentration of $15 \mathrm{ppm}$.

Growth of colonies from Aspergilius si Penicillium isolates in the presence of MCS was normal, which highlighted the tested product's lack of biocidal action. 
Test isolate sensitivity towards the two CS-based compounds was also expressed with the help of indicators EC50 and EC90 (Table 3). Test isolates sensitivity varied by species and product used. The Alternaria brassicicola isolate turned out to be the most sensitive towards CCS, with EC50 and EC90 values of $3.69 \mathrm{ppm}$ and $11.8 \mathrm{ppm}$ respectively, followed by Sclerotinia sclerotiorum with $6.34 \mathrm{ppm}$ and 11.88 ppm and by Botrytis cinereal with values of $7.32 \mathrm{ppm}$ and 12.43 ppm respectively. Botrytis cinerea (with EC50 and EC90 values of $6.58 \mathrm{ppm}$ and $13.19 \mathrm{ppm}$ respectively) and Sclerotinia sclerotiorum (with EC50 and EC90 values of $7.9 \mathrm{ppm}$ and $13.20 \mathrm{ppm}$ respectively) showed most sensitivity to MCS.

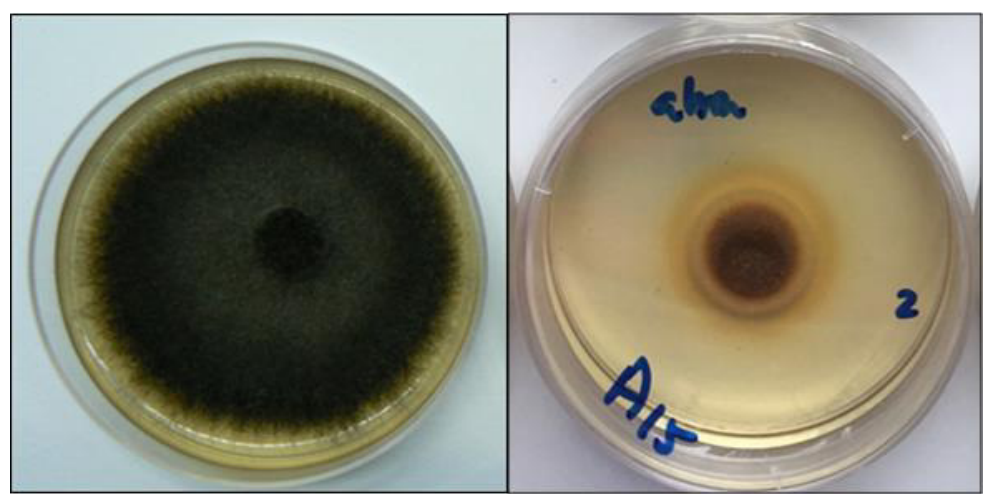

Fig. 1. Colony and spores morphology of Alternaria brassicicola on PDA from control and CCS $15 \mathrm{ppm}$

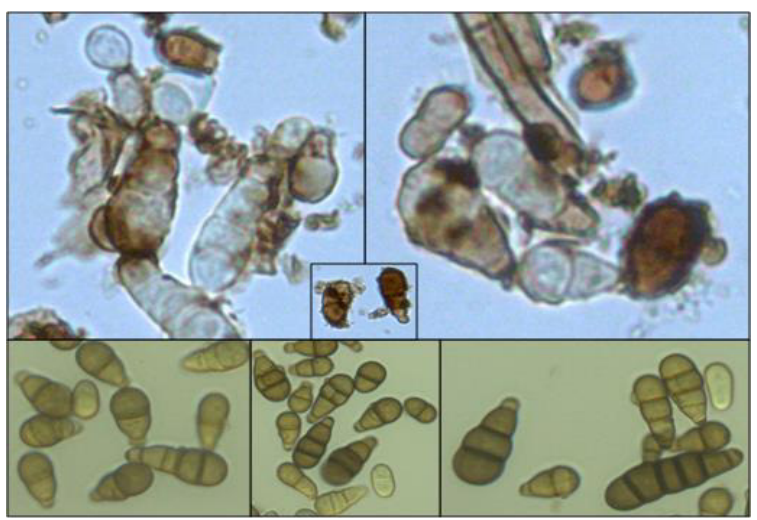

Fig. 2. Alternaria brassicicola denaturated spore cellular membrane of conidia on electronic microscope under CCS $15 \mathrm{ppm}$ (above) and normal cellular membrane (below)

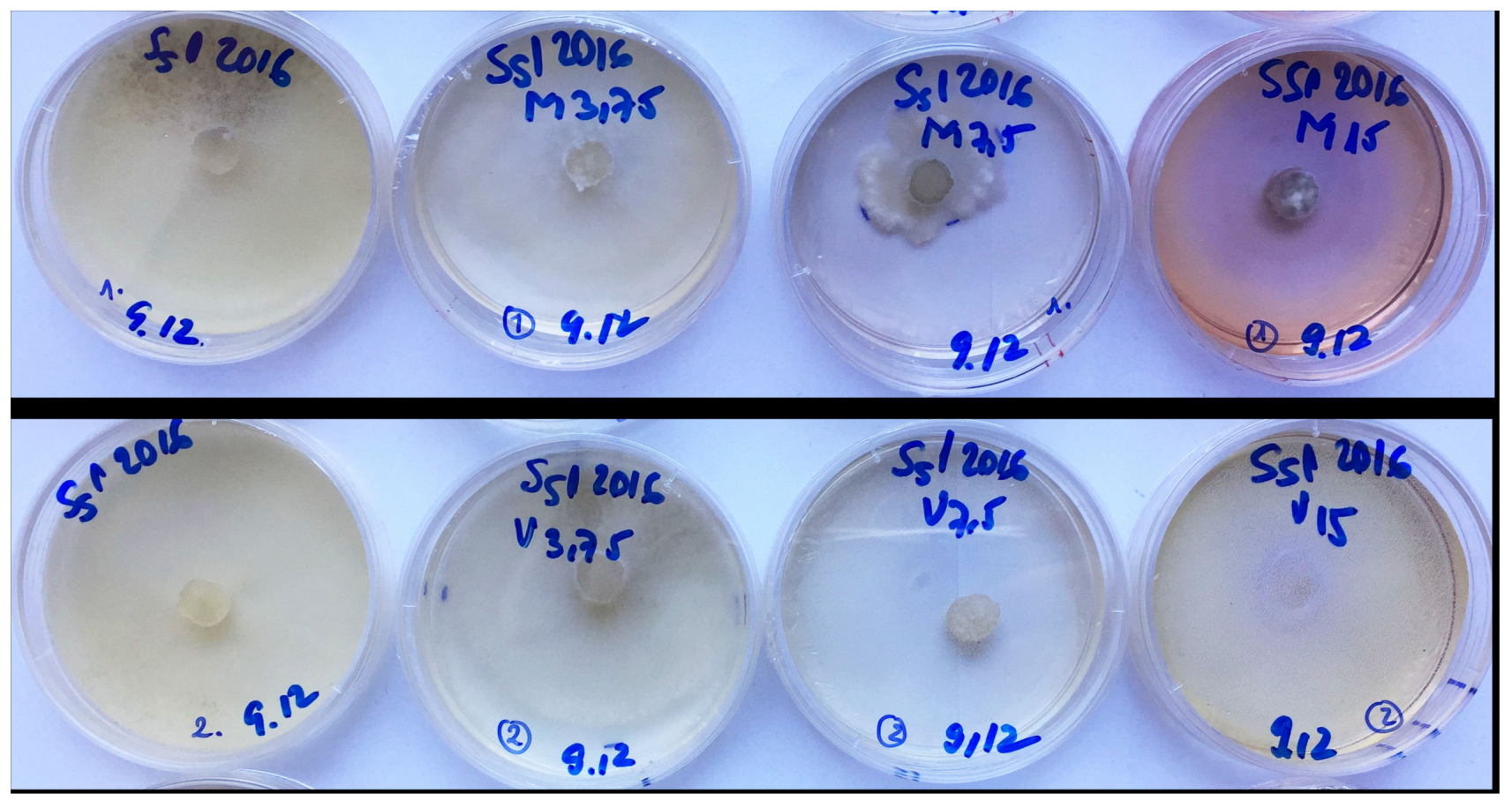

Fig. 3. Colonies of Sclerotinia sclerotiorum on PDA amended with colloidal silver (MCS and CCS) at $3.75 \mathrm{ppm}, 7.5 \mathrm{ppm}$ and $15 \mathrm{ppm}$ 
Table 1. Fungal isolates used in experiments

\begin{tabular}{cccc}
\hline Species & Isolate code & Host & Geographic origin \\
\hline Alternaria brassicicola & $\mathrm{Ab} 43$ & Raphanus sativus seeds \\
Botrytis cinerea & $\mathrm{Bcl}$ & Fycopersicum esculentum fruits \\
Fusarium culmorum & $\mathrm{F} 065$ & Raphanus sativus seeds \\
Fusarium oxysporum & $\mathrm{F} 1$ & Cucumis sativus & Romania \\
Aspergillus flavus & $\mathrm{Af}$ & Raphanus sativus seeds \\
Aspergillus niger & $\mathrm{Anl}$ & Raphanus sativus seeds \\
Penicillium digitatum & $\mathrm{Pd}$ & Citrus & Romania \\
Sclerotinia sclerotiorum & $\mathrm{Ss} 1$ & Cucumis sativus & Romania \\
\hline
\end{tabular}

Table 2. Effects of colloidal silver on the mycelial growth

\begin{tabular}{|c|c|c|c|c|c|c|c|}
\hline \multirow{4}{*}{ Species } & \multirow{4}{*}{ Isolate code } & \multicolumn{6}{|c|}{ Efficacy (mycelial growth inhibition) [\%] } \\
\hline & & \multirow{2}{*}{\multicolumn{3}{|c|}{$\begin{array}{l}\text { Craft colloidal silver } \\
\text { Concentration [ppm] }\end{array}$}} & \multirow{2}{*}{\multicolumn{3}{|c|}{$\begin{array}{c}\text { Medicer Colloidal silver } \\
\text { Concentration }[\mathrm{ppm}]\end{array}$}} \\
\hline & & & & & & & \\
\hline & & 3.75 & 7.5 & 15 & 3.75 & 7.5 & 15 \\
\hline Alternaria brassicicola & $\mathrm{Ab} 43$ & 38.96 & 85.71 & 100 & 23.38 & 29.87 & 36.36 \\
\hline Botrytis cinerea & $\mathrm{Bcl}$ & 1.94 & 81.55 & 100 & 19.42 & 75.73 & 94.17 \\
\hline Fusarium culmorum & F065 & 9.52 & 10.32 & 72.22 & 13.57 & 17.57 & 31.31 \\
\hline Fusarium oxysporum & Fol & 0 & 6.35 & 72.22 & 0 & 7.14 & 32.54 \\
\hline Aspergillus flavus & Av & 0 & 0 & 40.48 & 0 & 0 & 0 \\
\hline Aspergillus niger & Anl & 0 & 0 & 57.14 & 0 & 0 & 0 \\
\hline Penicillium digitatum & Pd & 0 & 32.46 & 76.19 & 0 & 0 & 0 \\
\hline Sclerotinia sclerotiorum & Ss 1 & 3.09 & 100 & 100 & 11.11 & 57.14 & 100 \\
\hline
\end{tabular}

Table 3. Responses of fungal isolates to colloidal silver

\begin{tabular}{|c|c|c|c|c|c|}
\hline \multirow[t]{2}{*}{ Species } & \multirow[t]{2}{*}{ Isolate code } & \multicolumn{2}{|c|}{$\begin{array}{l}\text { Craft Colloidal Silver } \\
\text { (CCS) }\end{array}$} & \multicolumn{2}{|c|}{$\begin{array}{l}\text { Medicer Colloidal Silver } \\
\text { (MCS) }\end{array}$} \\
\hline & & EC50 & EC90 & EC50 & EC90 \\
\hline Alternaria brassicicola & Abra 43 & 3.69 & 11.8 & 26.8 & 62.78 \\
\hline Botrytis cinerea & $\mathrm{Bcl}$ & 7.32 & 12.43 & 6.58 & 13.19 \\
\hline Fusarium culmorum & F065 & 11.99 & 18.70 & 26.83 & 51.6 \\
\hline Fusarium oxysporum & F1 & 12.27 & 18.19 & 21.16 & 34.66 \\
\hline Aspergillus flavus & $\mathrm{Av}$ & 18.21 & 28.59 & $>15$ & $>15$ \\
\hline Aspergillus niger & Anl & 14.43 & 21.78 & $>15$ & $>15$ \\
\hline Penicillium digitatum & Pd & 10.82 & 16.85 & $>15$ & $>15$ \\
\hline Sclerotinia sclerotiorum & Ssl & 6.34 & 11.88 & 7.9 & 13.2 \\
\hline
\end{tabular}

\section{Discussion}

This research aimed at pointing to the fungitoxic properties of colloidal silver on important plant pathogens for horticulture. Test isolates were selected according to their major impact on cultures, their presence during vegetation or post-harvesting period, and their transmission through infected seeds or soil. Fusarium mycelium representatives (Fusarium graminearum, Fusarium culmorum) are known for their aggressive attacks and their likeliness to generate mycotoxins - highly-dangerous secondary metabolites to be found in harvests and finite products (Semple et al., 1989).

Our results highlight the fungitoxic action of colloidal silver against most test isolates, with efficacy gaps being identified between Craft Colloidal Silver (CCS) and Medicer Colloidal Silver (MCS).

As far as we know, studies on the antimicrobial action of silver colloids against fungal plant pathogens are few, there being a lack of direct concern about the use of colloidal silver as natural biocide. Some studies underline the fungal/fungitoxic action of silver nanoparticles against plant pathogens, whether seedborne or found in the vegetation.

The results of our studies point to CCS efficacy in the complete mycelial growth inhibition (100\%) of Sclerotinia sclerotiorum (isolated from Cucumis sativus fruits), Alternaria brassicicola (isolated from Raphanus sativus seeds) and Botrytis cinerea (isolated from Lycopersicum esculentum fruits). We believe these results are the first to reveal the fungal action of CS against fungal; plant pathogens, for current studies only tackle the biocide potential of silver nanoparticles (Jung et al., 2010; Soltanloo et al., 2010; Lamsal et al., 2011; Kim et al., 2012; Ouda, 2014; Ziedan and Moataza, 2016).

Studies are being carried out to identify the CS action mechanism and its integration in the program for the protection of sustainable horticultural crops, as treatments to be applied on seeds, during the vegetation and the post- 
harvest period. First signs of CS treatment efficacy have been identified in controlling Pseudomonas syringae pv. actinidiae, the causal agent of bacterial canker of kiwi fruit (Drummond, 2011) or of silver nanoparticles efficacy in controlling pathogens of citrus fruits - Alternaria alternata and Penicillium digitatum (Salaheldin, 2016). Anthracnose attacks (Colletotrichum spp.) on paprika crops (Lamsal et al., 2011) or mildew attacks (Pseudoperonospora cubensis) on protected cucumber crops (Alavi and Dehpour, 2010) could also be prevented with silver nanoparticles. These results open new paths to studies in connection with the occurrence of new fungicide generations.

The impact of silver nanoparticles as biostimulators for seed germination and plant growth was highlighted. In this context, using CS to treat the seed against seed-borne pathogens may be an alternative to the traditional treatment. Preliminary results show that applying CCS 10 ppm on artificially-contaminated radish seeds decreased the incidence and symptoms severity of Alternaria brassicicola (data not shown).

\section{Conclusions}

According to our results, CS is highly-effective in inhibiting the mycelial growth of Alternaria brassicicola, Botrytis cinerea - two pathogens with already reported resistant isolates to active molecules used in current protection programs and Sclerotinia sclerotiorum, for which the chemical control is still a challenge. Studies currently in progress open up the possibility to include CS and other colloids in the protection programs for sustainable horticultural crops due to their antifungal properties. As for their use as plant protection products, risk parameters such as bioaccumulation, toxicity and remanence as yet to be determined.

\section{Acknowledgements}

The authors are thankful to Université d'Angers, France - IRHS 1345 for isolates.

\section{References}

Abdelmalek GAM, Salaheldin TA (2016). Silver nanoparticles as a potent fungicide for citrus phytopathogenic fungi. Journal of Nanomedicine Research3(5):00065.

Aktar W, Sengupta D, Chowdhury A. (2009). Impact of pesticides use in agriculture: their benefits and hazards. Interdisciplinary Toxicology 2(1):1-12.

Alavi SV, Dehpour AA (2010). Evaluation of the nanosilver colloidal solution in comparison with the registered fungicide to control greenhouse cucumber downy mildew disease in the North of Iran. Acta Horticulturae 877:1643-1646.
Drummond LN (2011). Colloidal silver - Use in kiwifruit; potential for use of colloidal silver as a pesticide to treat $P s a$ in kiwifruit vines. Drummond Food Science Advisory Ltd, Kiwifruit Vine Health, New Zeeland.

FRAC Code List (2018). Fungicides sorted by mode of action (including FRAC Code numbering). Retrieved 2018 February 16 from http://www.frac.info/docs/default-source/publications/frac-codelist/frac_code_list_2018-final.pdf?sfvrsn=6144b9a_2.

Gogos A, Knauer K and Bucheli TD (2012). Nanomaterials in plant protection and fertilization: current state, foreseen applications and research priorities. Journal of Agricultural and Food Chemistry 60(39):9781-9792.

Iacomi-Vasilescu B, Avenot H, Bataillé-Simoneau N, Laurent E, Guénard $\mathrm{M}$,Simoneau P (2004). In vitro fungicide sensitivity of Alternaria species pathogenic to crucifers and identification of Alternaria brassicicola field isolates highly resistant to both dicarboximides and phenylpyrroles. Crop Protection 23:481-48.

JungJH, Kim SW, Min JS, Kim YJ,Lamsal K, Kim KS, Lee YS (2010). The effect of nano-silver liquid against the white rot of the green onion caused by Sclerotium cepivorum. Mycobiology38(1):39-45.

Kim SW, Jung JH, Lamsal K, Kim YS, Min JS, Lee YS (2012). Antifungal Effects of Silver Nanoparticles (AgNPs) against Various Plant PathogenicFungi. Mycobiology 40(1):53-58.

Klasen HJ (2000). Historical review of the use of silver in the treatment of burns. I. Early uses. Burns 26(2):117-130.

Lamsal K, Kim SW, Jung J-H, Kim YS, Kim KS, Lee YS (2011). Application of silver nanaoparticles for the control of Colletotrichum species in vitro and pepper anthracnose disease in field. Mycobiology 39(3):194199.

Moore SL, Payne DN (2004). Types of antimicrobial agents. In: Russell, Hugo \& Ayliffe's Principles and Practice of Disinfection, Preservation \& Sterilization, Fourth Edition. Fraise AP, Lambert PA, Maillard J-Y (Eds). Blackwell PublishingLtd, Oxford, UK.

OudaSM (2014). Antifungal Activity of silver and cooper nanaoparticles on two plant pathoghens, Alternaria alternata and Botrytis cinerea. Research Journal of Microbiology9(1):34-42.

Semple RL, Frio AS, Hicks PA, Lozare JV (1989). Mycotoxin prevention and control in food grains. A collaborative publication of the UNDP/FAO Regional Network Inter-Country Cooperation on Preharvest Technology and Quality Control of Foodgrains (REGNET) and the ASEAN Grain Postharvest Programme, Bankok, Thailand.

Soltanloo H, Alimohammadi M, Ramezanpour S, Bagher M, Najar B (2010). Nanosilver colloid: a novel antimicrobial candidate applicable in plant tissue culture. Australian Journal of Basic and Applied Sciences 4(10):5338-5345.

Ziedan EHE, Moataza MS (2016). Efficacy of nanoparticles on seed borne fungi and their pathological potential of cucumber. International Journal of Pharm Tech Research 9(10):16-24. 